\title{
O ÍNDICE DE UM ENIGMA: O INCONSCIENTE E O FENÔMENO DA PREMONIÇÃO
}

Ronaldo Manzi Filho

Ronaldo Manzi Filho Doutor em Filosofia pela Universidade de São Paulo e pela Radboud Universiteit Nijmegen. Co-organizou os livros A filosofia após Freud (Humanitas) e Paisagens da fenomenologia francesa: vida, percepção e ontologia (UFPR).
RESUMO: Em 1953, Devereux editou uma coletânea de textos de Freud sobre a psicanálise e o ocultismo. Apesar de pouco conhecidos, tais escritos foram fundamentais no debate com a filosofia francesa. Merleau-Ponty, por exemplo, debruçou-se sobre esta questão duas vezes: primeiro, relacionando a premonição com a percepção. Depois, a telepatia ao sentir. Sua conclusão nos leva a repensar o tema central da psicanálise: o inconsciente. Sua proposta é relacioná-lo à indivisão do sentir e à sua reversibilidade: vejo e sou visto.

Palavras-chave: Premonição, telepatia, inconsciente, sentir, ver e ser visto.

ABSTRACT: The index of an enigma: the unconscious and the phenomenon of premonition. In 1953, Devereux edited a collection of Freud's texts on psychoanalysis and the occultism. Despite these texts being little known, they were crucial in the debate with the French philosophy. Merleau-Ponty, for instance, addressed this issue twice. At first, relating the premonition with perception. At another time, he links the telepathy with the sense. His conclusion leads us to rethink the focus of psychoanalysis: the unconscious. His proposal is to link it with the unity of the sense and its reversibility: to see and being seen.

Keywords: Premonition, telepathy, unconscious, sense, see and being seen. 
E m 1922, Freud age como se fosse necessário responder a um fenômeno de sua época (e que ainda me parece bastante pertinente entre nós hoje):

"no presente momento, quando tão grande interesse é sentido naquilo que denominamos fenômeno 'oculto', muitas antecipações definidas serão indubitavelmente despertadas pelo anúncio de um texto com esse título [Dreams and Telepathy]. Vou por isso dirigir-me a essas pessoas para explicar que não há fundamento para nenhuma destas antecipações. Você não aprenderá nada neste texto meu sobre o enigma da telepatia; na verdade, você nem irá coletar dados se eu acredito na existência da ‘telepatia' ou não.” (FREUD, apud DEVEREUX, 1953, p.69)

Por mais claras que sejam estas palavras, na verdade, é difícil compreender a posição freudiana diante disso. Foram tantas as cartas de elogios e convites para que Freud participasse de eventos sobre ocultismo, que se sentiu no "dever" de esclarecer o suposto mal entendido: a psicanálise não tem nada a ver com o ocultismo e, se há algo de obscuro em sua teoria, trata-se do seu próprio objeto de estudo: o inconsciente. Em uma coletânea sobre esse tema publicado em 1953, editada por George Devereux, há passagens como esta: “é uma esperança em vão que o trabalho analítico poderia escapar deste colapso de valores simplesmente porque seu objeto é o misterioso inconsciente" (FREUD, apud DEVEREUX, 1953, p.69). Mas, diante desse objeto misterioso, Freud parece não deixar clara a posição da psicanálise diante do ocultismo. Como entender esse fenômeno?

Minha sugestão neste artigo é tomarmos a interpretação de Maurice MerleauPonty. Aparentemente, isso parece trazer mais problemas do que esclarecimentos, pois teremos que investigar também de que maneira o filósofo incorpora a visão freudiana desse fenômeno - ainda mais se levarmos em conta que Merleau-Ponty não só assimila esse estudo de Freud em seu trabalho como aproxima a filosofia e o ocultismo, ao responder, por exemplo, “o que é a Filosofia? O domínio do Verborgen ( $\phi$ e ocultismo)”. (MERLEAU-PONTY, 1964/2004b, p.234)

No entanto, como diz Bernard Baas, talvez o modo de confrontar a filosofia e a psicanálise não possa ocorrer de outra maneira, pois "Freud não duvidaria por nenhum instante: a aposta num confronto entre a psicanálise e a filosofia não pode ter outra questão senão o inconsciente”. (BAAS, 1998, p.1)

Essa definição merleau-pontyana da filosofia, sem dúvida nenhuma, merece alguns esclarecimentos. Lida sem referência ao seu contexto, poderíamos tender a pensar que sua filosofia é adepta de algum tipo de ocultismo, como se sua experiência filosófica nos levasse a estudos de domínio desconhecido aos quais não teríamos acesso, senão por vias obscuras. Por um lado, essa impressão não é totalmente errônea — a filosofia é, para Merleau-Ponty, um domínio obscuro no 
qual é preciso um contato criativo, já que "o ser é aquilo que exige de nós criação para que tenhamos dele experiência”. (MERLEAU-PONTY, 1964/2004b, p.248)

De fato, ao ler a obra de Merleau-Ponty temos a impressão de que a filosofia é esse domínio do Verborgen. Basta lembrar que estamos sob a esfera de um ser bruto e de um elemento: a carne. Sendo assim, seu próprio objeto de estudo é obscuro. Por que, então, relacionar a filosofia ao obscuro? Acredito que o motivo desta aproximação possa ajudar a compreender o fenômeno do ocultismo de um novo modo.

Lembremos, antes, que “infelizmente”, Freud admite não ter verificado muitos desses casos em sua clínica, limitando-se aos poucos com que teve contato. Ele pretendia mostrar como estes casos podem ser explicados a partir do conceito de inconsciente. Ou seja, toda questão gira em torno do inconsciente. Sendo assim, como pensá-lo?

Freud não esconde que o fenômeno da telepatia, em alguns casos, parece realmente mostrar que há uma comunicação dos inconscientes:

“o evento pode ser plenamente esclarecido se estamos dispostos a assumir que o conhecimento foi transmitido do cliente ao pretenso profeta por caminhos desconhecidos, e por meios outros que não as formas conhecidas de comunicação. Isso, por sua vez, parece trazer a conclusão de que transmissões de pensamento existem. (...) As análises revelam isso, que aquilo que foi transmitido indutivamente de uma pessoa a outra não foi somente um vestígio avulso de informação causal. Pelo contrário, foi algo muito desejado, que ficou numa relação especial com a consciência, e que encontra uma expressão consciente, embora ligeiramente disfarçada, em outra pessoa." (FREUD, apud DEVEREUX, 1953, p.62)

Entretanto, em nenhum momento Freud se “arrisca” a descrever como é possível essa comunicação - apenas afirma que ela ocorre por caminhos desconhecidos, tal como pela percepção sensorial.

Merleau-Ponty tenta explicar essa comunicação entre os inconscientes em dois momentos de sua experiência filosófica. Num primeiro momento, descreve a interpretação freudiana da comunicação entre os inconscientes pela percepção. Menos de cinco anos depois, retoma o assunto, mas acrescenta que isso só poderia ser possível se compreendêssemos o inconsciente enquanto um fenômeno do sentir.

No seu curso sobre Le problème de la passivité — le sommeil, l’inconscient, la mémoire (1954-1955), Merleau-Ponty interpreta, em especial, um texto de Freud, traduzido por James Strachey como A premonitory dream fulfilled, datado de 1899 (texto, aliás, indexado à Die Traumdeutung). 
Trata-se da experiência de uma senhora, denominada senhora B, que relata um sentimento de premonição. A senhora B narra a Freud um sonho em que encontra, numa rua específica, o Dr. K, antigo médico da família. Segundo seu relato a Freud, o encontro de fato ocorreu, no dia seguinte, naquela rua: "vendo-o, ela se sentiu convencida que ela tinha sonhado uma noite antes que esse encontro aconteceria nesse ponto preciso”. (FREUD apud DEVEREUX, 1953, p.49)

Para compreender o fato, Freud busca interpretar episódios anteriores relacionados ao Dr. K. Foi ele quem cuidou do marido da senhora B durante uma tuberculose. Obrigada a trabalhar como professora de música, visto que seu marido havia perdido sua fortuna, foi também o Dr. K quem a ajudou a encontrar os primeiros pupilos. A senhora B relata ainda a existência de outro Dr. K, advogado, que a auxiliou a organizar seus negócios arruinados e por quem se apaixonou. Todavia, devido à sua educação, não se entregou a esse sentimento enquanto estava casada, nem mesmo depois de enviuvar.

Descreve então outro acontecimento sentido como premonitório: um dia, durante o período em que perdera o marido, pensava no advogado quando ele, de repente, veio visitá-la. Vinte e cinco anos se passaram entre essa cena e o sonho. A senhora B casa-se novamente e, quando seu marido morre, herda sua fortuna. O advogado K é quem passa a administrar seus bens.

Freud faz uma suposição para explicar as premonições da senhora B: a segunda premonição lhe parece algo comum em qualquer história de amor, pois é normal que uma pessoa apaixonada fique pensando em quem ama. Entretanto, na situação inicial, há uma espécie de associação entre o tempo em que seu primeiro marido vivia e durante o qual ambos os senhores $\mathrm{K}$ a ajudavam.

Freud supõe que a senhora B normalmente sonhava com o advogado, e sofria porque isso é “(...) uma parte tardia de punição que a mulher paga por sua crueldade juvenil” (FREUD, apud DEVEREUX, 1953, p.50). Contudo, tais sonhos provavelmente eram colocados de lado quando ela acordava, já que não queria continuar a pensar nesse período da sua vida. Ao encontrar com o médico $\mathrm{K}$, que ela associa imediatamente àquele período: “(...) ele tem sido frequente em seus pensamentos, e talvez também em seus sonhos, como uma figura num fundo de um quadro em que ela esconde o amado figurado como o outro Dr. K” (idem).

Para Freud, foi isso que aconteceu: ao encontrar o médico, a senhora B deve tê-lo associado a um sonho que colocou de lado e, assim, acreditou que havia, de fato, sonhado na noite anterior com esse acontecimento. "Mas esta lembrança teve que sofrer a distorção da qual o sonho só escapara por ter sido completamente esquecido" (idem). Assim, conclui o psicanalista, o conteúdo do sonho - o encontro - foi transferido para uma crença - a de que teria realmente sonhado com esse encontro. 
Ora, o sentimento de premonição seria apenas a impressão de que o sonho foi realizado, quando, na verdade, foi associado, transferido para uma crença. Freud explica isso em termos da censura: "assim, a criação do sonho após o acontecido, única coisa que torna possíveis sonhos proféticos, nada mais é do que uma forma de censura, que torna possível ao sonho irromper na consciência”. (FREUD, apud DEVEREUX, 1953, p.51)

A passagem que encontramos em Das Unheimliche (não por acaso, num texto que diz sobre o que nos é estranho e, ao mesmo tempo, próximo), de 1919, é clara:

“(...) assim, temos personagens que devem ser considerados idênticos porque parecem semelhantes, iguais. Essa relação é acentuada por processos mentais que saltam de um para outro desses personagens - pelo que chamaríamos de telepatia —, de modo que um possui conhecimento, sentimento e experiência em comum com o outro. Ou é marcada pelo fato de que o sujeito identifica-se com outra pessoa, de tal forma que fica em dúvida sobre quem é o seu eu (self), ou substitui o seu próprio eu (self). E, finalmente, há o retorno constante da mesma coisa - a repetição dos mesmos aspectos, ou características, ou vicissitudes, dos mesmos crimes, ou até dos mesmos nomes, através das diversas gerações que se sucedem." (FREUD, 1919/1996, p.252)

Merleau-Ponty retoma essa curiosa experiência para explicar o que compreende por inconsciente, e confirma dois pontos da interpretação freudiana:

1) a possibilidade de haver sonho premonitório sem que haja o encontro com o advogado (deslocamento);

2) o deslocamento do desejo: o encontro com o médico associado ao amor de outrora.

Para Merleau-Ponty é, sim, possível que o desejo seja sentido como telepático: “a impressão constante de destino é, no fundo, a consciência do desejo indestrutível, de 'toda potência do desejo”” (MERLEAU-PONTY, 1954-1955/2003, p.220). Entretanto, a seu ver, não é preciso dizer do trabalho da censura, tal qual Freud desenvolve, como se a construção do sonho fosse tarefa sua.

Para o filósofo, esse trabalho é artificial — poder-se-ia explicá-lo em termos da percepção. De fato, a senhora B pode ter sentido o encontro como uma premonição, contudo, “a possibilidade desta ilusão sobre si deve ser fundamentada, e fundamentada sobre a dialética da consciência perceptiva: a verdade é percebida por ela, não conhecida" (MERLEAU-PONTY, 1954-1955/2003, p.220). Algo como se a senhora B não soubesse (mas teria, de certo modo, percebido) que, no fundo, teria trocado o médico pelo advogado. Tal como algo não percebido, 
“consequentemente, ele só os pode associar à mesma pessoa pela [tese de uma] falsificação deliberada (censura que sabe o que ela suprime). Para mim, mesmo no nível da 'consciência', [tomo] contato com a verdade e, por consequência, esta verdade não estaria num inconsciente recalcado fora de qualquer apreensão, mas se trataria de um contato perceptivo que não é um saber." (MERLEAU-PONTY, 1954-1955/2003, p.220-221)

Do seu ponto de vista, seria mais interessante pensarmos na temporalidade como o próprio Freud parece sugerir em Premonitions and chance: “(...) a ilusão do sonho profético ao ver o amigo de tempos remotos é talvez equivalente à fala que se segue: 'Ah, doutor, agora você me lembra de tempos atrás, quando eu nunca tinha que esperar em vão por N. quando tínhamos arranjado um encontro" (FREUD, apud DEVEREUX, 1953, p.54).

Já nas palavras de Merleau-Ponty: “a lembrança de alguém é uma lembrança de todo um tempo da vida, de um eu do passado, de um drama ou acontecimento, K2 que ela reencontra faz reviver este drama” (MERLEAU-PONTY, 1954-1955/2003, p.221). Ou seja, há uma impercepção, na premonição, de um drama vivido, e que é reativado no encontro com o médico — reativação que pressupõe uma história sedimentada. O deslocamento do médico com o advogado não é da ordem da associação mecânica entre K1 e K2, nem da síntese de um com o outro: "há o drama deste período de sua vida que é matriz simbólica, comandando todas as percepções e no que K1 e K2 estão implicados, que subsiste nela sob a forma de uma generalidade, de uma zona sensível, e sensível tanto a comparsas como ao autor principal” (MERLEAU-PONTY, 1954-1955/2003, p.221).

Essa implicação não precisa, para o filósofo (nessa época), ser pensada como um ato inconsciente. Diante disso, o que seria esta substituição? Segundo o filósofo, o desejo de encontrar K1 e substituí-lo por K2 não estaria escondido no inconsciente, mas exprimiria a essência da ocasião desejada, um encontro desejado que se apresenta como sonho e que é vivido como premonição. Como se esse encontro realizasse uma espécie de "milagre" — uma telepatia. Por isso, pensar no drama que é reativado ao reencontro — um passado que se desenvolve e que exige voltar à tona: “(...) isto não pode ser por acaso, isto estava inscrito na estrutura secreta do mundo, isto estava escrito, então visível, então sonhei com isto”. (MERLEAU-PONTY, 1954-1955/2003, p.222)

Com essa interpretação sob a lente da percepção, Merleau-Ponty acredita estar sendo fiel à análise de Freud. A seu ver, ele só estaria utilizando teorias que o próprio Freud tendia a desenvolver (MERLEAU-PONTY, 1954-1955/2003, p.222).

Outro exemplo de Freud que parece confirmar esta ideia é sobre a alucinação negativa. Trata-se do relato do psicanalista sobre outro fenômeno que poderia ser 
sentido como uma premonição. Freud diz que, poucos dias depois de ganhar o título de Professor, estava pensando num casal que, poucos meses antes, o havia procurado. Imediatamente, viu-os na rua.

Freud explica esse fato como uma percepção não reconhecida, ou seja, havia visto o casal a alguns metros à sua frente, mas não os tinha reconhecido. Entretanto, essa percepção o teria levado a lembrar-se deles: “mas esta percepção, seguindo o modelo da alucinação negativa, foi posta de lado por algum motivo emocional acentuado, e assim, sustentou a si mesmo espontaneamente como uma fantasia que emerge" (FREUD, apud DEVEREUX, 1953, p.54). MerleauPonty observa: “a percepção negativa e dupla de uma totalidade positiva, em todo caso ela é lacunar ou desvio em relação a um todo conhecido de seu estilo - A alucinação negativa: o que é alucinação nela, não conforme ao dado, é o não reconhecimento (...)”. (1954-1955/2003, p.264)

Entretanto, essa análise de Merleau-Ponty parece deixar de lado o que realmente é obscuro na telepatia: o que Freud descreve como uma comunicação entre os inconscientes. É certo que a premonição parece ser passível de ser explicada como um fenômeno perceptivo, tal como vimos, mas há casos em que parece haver, de fato, uma comunicação entre inconscientes. Vejamos uma passagem de Freud a título de exemplo:

“tenho frequentemente uma impressão, no curso de experimentos no meu círculo privado, que lembranças disfarçadas de emoções fortes podem ser transferidas com sucesso sem muita dificuldade. Se alguém tem a coragem de submeter a um exame analítico as associações de uma pessoa para quem os pensamentos são supostamente transferidos, correspondências frequentemente vêm à luz que, de outro modo, permaneceriam não descobertas. Com base em muitas experiências sou inclinado a chegar à conclusão que pensamentos que transferem deste tipo surgem particularmente fácil no momento em que uma ideia emerge do inconsciente ou, em termos teóricos, como se passa dos 'processos primários' aos 'processos secundários'." (FREUD, apud DEVEREUX, 1953, p.89)

Diante desse fenômeno, parece que Merleau-Ponty, menos de cinco anos depois daquelas interpretações, não hesita em descrever essa comunicação tal como se dá no sentir:

“Freud; comunicação dos inconscientes sem que a mensagem seja decifrada por uma percepção sensível. Mas a percepção, ela mesma, comporta esta mesma estrutura: aquilo que vejo, vejo-o como espetáculo para os outros, porque há um Einfühlung [acoplamento] com ele e através dele com os outros sentir." (MERLEAU-PONTY, 1956-1960/1995, p.351-352) 
O que isso significa? Parece-me que o filósofo, aqui, amplia o problema. Não se trata somente de uma percepção-impercepção. Posso sentir esse fenômeno (como dirá: sinto minha nuca queimando).

Ora, essa "ampliação” do problema nos diz algo: o enigmático fenômeno inconsciente só poderia ser descrito a partir do mundo sensível. O curioso é que o próprio Freud parece permitir essa associação ao relacionar a telepatia com a sensibilidade perceptiva. Que se veja essa passagem, por exemplo: “mas nesse ponto é preciso deixar bastante claro que ninguém tem até hoje mantido que o fenômeno da telepatia — a recepção de um processo mental de uma pessoa para outra por meios outros senão pela percepção sensorial — é exclusivamente relacionado aos sonhos”. (FREUD apud DEVEREUX, 1953, p.88)

Por que então Merleau-Ponty não explica esse fenômeno nos termos da percepção, e sim do sentir? A meu ver, por desenvolver ao extremo o que a percepção nos ensina: um fenômeno da reversibilidade. Perceber implica também ser visto; assim, implica o fenômeno do sentir.

Há um exemplo que Merleau-Ponty explora em vários momentos que nos ajuda a compreender esse fenômeno. Trata-se de uma mulher que se sente olhada. Melhor, de uma mulher que se sente olhada sem que saiba se está sendo vista ou não - uma sensação de estar sendo olhada por alguém. Seria esse o exemplo mais claro da telepatia para Merleau-Ponty.

Um modo de dizer que a sensorialidade de outrem implica na minha sensorialidade: ver é também sentir que sou ameaçado de ser visto. Vale a transcrição da nota abaixo, de abril de 1960 (publicada em 1964), denominada Télépathie Être pour autrui - Corporéité:

“órgão para ser visto (Portmann) — Meu corpo como órgão para ser visto - I.e.: perceber uma parte do meu corpo e assim a perceber como visível, i.e. para outrem. E claro ela toma esse caráter porque, efetivamente, qualquer um a vê — Mas este fato da presença de outrem não seria ele mesmo possível se previamente a parte do corpo em questão não fosse visível, se não tivesse, em torno de cada parte do corpo, um halo de visibilidade (...). Esta visibilidade de meu corpo (para mim — mas também universal e, eminentemente, para outrem) é ela que faz aquilo que se denomina telepatia. Pois é suficiente uma ínfima indicação da conduta de outrem para ativar este perigo da visibilidade. P.ex. uma mulher sente seu corpo desejado e olhado por sinais imperceptíveis, e sem mesmo ela mesma olhar quem a olha. A 'telepatia' tem aqui aquilo que ela alcança na percepção efetiva por outrem (erotomania). cf. Psychoanalysis and the occult - Sentimo-nos olhados (nuca queimando) não porque algo passa do olhar ao nosso corpo e vem queimar o ponto visto, mas porque sentir seu corpo é sentir também seu aspecto para outrem. Seria preciso aqui buscar em qual sentido a sensorialidade de outrem está implicada na minha: sentir meus olhos é 
sentir que eles estão sendo ameaçados de serem vistos - Mas a correlação não é sempre assim daquele que vê ao que é visto ou de falar a compreender: minhas mãos, meu rosto são também do visível. O caso da reciprocidade maior e perfeita em que há quase reflexão(Einfühlung), Ineinander, o caso geral é arranjo de um visível para mim a um tangível para mim e deste visível para mim a um visível para outrem - (p.ex. minha mão).” (MERLEAU-PONTY, 1964/2004b, p.293-294)

Em primeiro lugar, percebamos que essa referência a Portmann não é por acaso. Por que associar um estudo sobre a aparência dos animais (Die Tiergestalt - Studien über die Bedeutung der tiersichen Erscheinung) com esse exemplo da mulher que sente ser vista? O que nos diz Portmann?

Na verdade, Merleau-Ponty realiza uma interessante interpretação dos trabalhos de Portmann sobre a relação da aparência dos animais e sua proximidade com as obras de arte. "Portmann a interpreta, não como uma finalidade do artista, mas como referência do corpo visível ao olho de um congênere que o verá” (MERLEAU-PONTY, 1957-1958, p.106). O fato de a aparência dos animais ser uma expressão de formas, pode nos levar a pensar que há uma espécie de comunicação a partir do que um animal se mostra a outro. Como se a aparência dos animais, seus ornamentos, fosse um órgão de comunicação aos olhos de outro de sua espécie — literalmente, órgãos visuais, como, por exemplo, a sua plumagem.

Desse modo, fica claro que, segundo Portmann, essa aparência é formada com um objetivo específico: “(...) com vistas à visibilidade” (PORTMANN, 1967, p.22). Ou seja, estamos diante de um “órgão para ser visto”: um esquema óptico. (PORTMANN, 1967, p.122)

Ora, se o próprio corpo é um órgão visual, uma espécie de comunicação que os animais realizam uns com os outros, o mesmo não se daria no homem? Não seria isso que Merleau-Ponty estaria defendendo ao relacionar esse fenômeno do mundo animal com o ocultismo na psicanálise?

Voltemos ao exemplo da mulher que se sente olhada. A telepatia seria esse estranho fenômeno pelo qual esta mulher sente seu corpo desejado e olhado. Trata-se, literalmente, de um fenômeno do sentir — ela se sente olhada. Quando Merleau-Ponty diz que "vejo e sou visto”, que ambos estamos numa relação promíscua, afirma, no fundo, que é impossível que eu veja sem ter essa sensação de ameaça de ser visto, porque esse fenômeno é reversível. Trata-se do que o filósofo define como uma indivisão sentir, um fenômeno exemplificado no tocar das mãos:

"quando eu toco minha mão esquerda com minha mão direita, minha mão tocante apreende minha mão tocada como uma coisa. Mas de repente, sou advertido que minha mão esquerda se coloca a sentir. As relações se invertem. Fazemos a 
experiência de um recobrimento entre a contribuição da minha mão esquerda e aquela da minha mão direita, e de um recobrimento de suas funções. Esta variação mostra que se trata sempre da mesma mão.” (MERLEAU-PONTY, 1956-1960/1995, p.107-108)

Mas, mesmo que esse corpo seja capaz de ser sentido, ele também é um corpo que sente: esta é a indivisão do sentir. Ora, quando toco minha mão direita na esquerda toco e sou tocado. Quando toco a mão de outrem, toco e sou tocado. O mesmo fenômeno que acontece em mim, ocorre também nessa relação com outrem. É isso que Merleau-Ponty define como uma indivisão do sentir — só posso sentir (tocar e ser tocado) se outrem também sentir (tocar e ser tocado). A seus olhos, é impossível pensar o sentir fora dessa indivisão.

Desde seus primeiros escritos, Merleau-Ponty destaca que apenas através do sentir é possível acessar a outrem, e como esse sentir apresenta-se tal qual um prolongamento. É nesse prolongamento, na verdade, nessa indivisão, que compreendemos que jamais podemos dizer que vemos sem sermos vistos (assim como na aparência dos animais), pois se trata de algo constitutivo do visível: uma generalidade do sentir. Uma generalidade na qual estamos "mergulhados" e nos tornando visíveis (participantes da indivisão do sentir).

Percebamos por que Merleau-Ponty insistia tanto no exemplo das mãos: essa é uma experiência clara do fenômeno da indivisão. Indivisão essa que ocorre também entre eu e outrem (só o vejo porque sou visto). Indivisão também pensada como prolongamento, e mesmo, como um sistema de equivalências entre o dentro e o fora (MERLEAU-PONTY, 1968, p.178).

Como vemos, Merleau-Ponty define o sentir a partir da noção de Ineinander, ou seja, numa promiscuidade entre o dentro e o fora, entre eu e outrem. Ora,

“Ineinander é possível porque o corpo sensorial é relação de indivisão a si -É o sentido do esquema corporal - uma relação de ser corpo-mundo e aspectos do corpo, uma relação de ejeção-introjeção, reciprocidade dentro-fora. Incorporação — (as coisas (Schilder) — hábitos) — E, inversamente, expulsão (...).” (MERLEAUPONTY, 1959-1960, p.84)

Vale nos determos neste ponto: trata-se de um movimento de inerência de um no outro, de um entrelaçar-se ou um emaranhar-se. Noutras palavras, o sentir é o movimento de indivisão, de inerência um no outro, de ver e ser visto, de projeção-introjeção corporal. Enfim, de um Ineinander entre o dentro e o fora.

Por isso, Merleau-Ponty irá falar de um império entre eu e outrem: 
“introduzir o inconsciente, não atrás de nós, mas diante de nós como pivô ou entre-dois de nosso mundo percebido, Urgemeinschaftung [vida em comum primitiva] de nossa vida, lugar de projeção-introjeção: nós somos somente repartições deste império único eu-outrem, dessa cadeia falar-responder.” (MERLEAU-PONTY,1959, noté 8 par B.N.)

Uma vez que acompanhamos essa indivisão do sentir, segundo Merleau-Ponty, não há porque não explorá-lo em termos do inconsciente, já que o inconsciente é o sentir segundo suas palavras: ter um corpo é participar dessa charnière, ou seja, participar de uma espécie de transição, que está entre-dois e que se reatualiza a cada articulação:

“o oculto na psicanálise (o inconsciente) é deste modo (cf. uma mulher na rua sentindo que se olha seu peito e verificando sua vestimenta. Seu esquema corporal é para si, para outrem — É uma transição [charnière] do para si e para outrem) Ter um corpo, é ser visto (não é somente isto), é ser visível — Aqui a impressão de telepatia, do oculto = vivacidade na leitura muito rápida do olhar de outrem." (MERLEAU-PONTY, 1964/2004b, p.240)

Nesses termos, podemos dizer que o inconsciente participa da lógica, muda do corpo ou de um simbolismo sem palavras, pois de algum modo, há um simbolismo corporal. Para Merleau-Ponty, é isso que parece sugerir Freud, por exemplo, nesta passagem: "tendo olhos para ver e ouvidos para escutar, não tarda qualquer um em se convencer de que os mortais não podem ocultar segredo algum. Aqueles, cujos lábios calam, falam os dedos. Todos os movimentos o delatam” (FREUD, 1905/1953, v. 15, p.70).

Isto é, aquilo que meu corpo expressa já vale para mim, mesmo que eu não o coloque em palavras. A impressão de telepatia expressa exatamente isto: não só que os “dedos falam”, mas que eu sei, de algum modo, o que eles estão falando. Ter um corpo é participar dessa comunicação, saber que se está sendo visto, sentir que se é olhado, porque se está "condenado" ao mundo da visibilidade. Não a experiência de ser olhado pela fechadura, tal como Sartre descreve, mas a implicação de ter/ser um corpo, algo que vê e é visto.

É esta implicação que Merleau-Ponty nos aponta, agir sobre outrem, participar do mundo da visibilidade, do sentir, em que um inconsciente age noutro sem que ambos tenham consciência:

“(...) ignorar aquilo que se vê, é o ver (consciência 'muda', simbolização que não tem necessidade da linguagem e que lhe é rebelde à primeira vista, porque ela é já simbolização sem palavras, centração de todo o esquema corporal, realização de 
sintomas, lógica muda do corpo — mas aqui saímos de um inconsciente de estado — Estupor, onirismo do sentir — o sentir é tipicamente do inconsciente. Freud: o inconsciente pode agir sobre um outro inconsciente sem ser decifrado pelas duas consciências presentes (...).” (MERLEAU-PONTY,1959-1960, p.86)

Já na Phénoménologie de la perception, Merleau-Ponty destaca um fenômeno curioso: a heautoscopia, ou seja, a percepção por um sujeito de seu próprio corpo fora de si, que ele entende como num espelho, como se o sujeito se sentisse duplicado. Nesse momento, Merleau-Ponty estava preocupado em descrever a percepção externa e a percepção do próprio corpo, tentando mostrar como as duas percepções são faces de um mesmo ato (1945/1967, p.237). Entretanto, nesta passagem, faz uma observação que será uma das maiores peças de sua filosofia futura. Leiamo-la:

"na heautoscopia, antes de ver a si mesmo, o sujeito passa sempre por um estado de sonho, de devaneio ou de angústia e a imagem de si mesmo que aparece fora não é senão o verso desta despersonalização [Lhermitte]. O doente se sente no duplo que está fora dele como num elevador que sobe e para bruscamente, sinto a substância do meu corpo escapar de mim pela minha cabeça e ultrapassar os limites do meu corpo objetivo. É no meu corpo próprio que a doença sente a aproximação deste Outro que ele jamais viu pelos seus olhos, como o normal reconhece por certa queimadura na sua nuca que alguém atrás dele o olha [Jasper]." (MERLEAUPONTY, 1945/1967, p.238)

Ora, esse doente descrito que sente a aproximação deste Outro e o sujeito normal que reconhece certa queimadura em sua nuca quando alguém atrás dele o olha, são exemplos maiores do que será a dimensão de Visibilidade da carne - o olhar apalpa: a nuca queima. O que ali não passava de exemplo, será agora uma das questões fundamentais na sua experiência filosófica. Isso, que se passa como um fenômeno patológico ou casual na vida cotidiana, revela-se um dos fenômenos do sentir. Merleau-Ponty age aqui como se tivesse levado ao extremo esse fenômeno para mostrar, tal como na bela metáfora de Freud, as linhas de clivagens presentes num cristal, invisíveis, que só aparecem ao jogá-lo no chão. A qual fenda estamos nos referindo?

O fenômeno da telepatia foi o primeiro modo de vermos as consequências de afirmarmos que somos seres que veem e que são vistos. Ou seja, somos condenados a sermos vistos. Estamos, a todo o momento, ameaçados de sermos vistos, como no exemplo da mulher que se sente olhada. Mais do que uma ameaça de sermos vistos pelo buraco da fechadura, somos, literalmente, vistos 
pelo mundo. Talvez essa seja a passagem mais famosa e mais complexa de Le visible et l'invisible:

“de modo que aquele que vê está pego naquilo que ele vê, é ainda ele mesmo que ele vê: há um narcisismo fundamental de toda visão; e pela mesma razão, a visão que ele exerce, ele é submetido também pelas coisas que, como disseram,eu me sinto olhado pelas coisas, que minha atividade é identicamente passividade - o que é o sentido segundo e mais profundo do narcisismo: não ver o exterior, como os outros o veem, o contorno de um corpo que se habita, mas, sobretudo ser visto por ele, existir nele, emergir dele, ser seduzido, captado, alienado pelo fantasma, de modo ver e ser visto se reciprocam e não sabemos mais quem vê e quem é visto. É esta Visibilidade, esta generalidade do Sensível em si, este anonimato inato de Mim-mesmo que denominamos carne a todo o momento, e sabemos que não há um nome na filosofia tradicional para designá-la." (MERLEAU-PONTY, 1964/2004a, p.181)

São quatro os pontos que não podemos deixar de explorar aqui: 1) O narcisismo da visão; 2) o fato de se sentir olhado pelas coisas; 3) o ser seduzido, captado, alienado pelo mundo, em que não sei quem vê e quem e visto; 4) a generalidade do sensível (Visibilidade) que implica num anonimato de mim mesmo.

$\mathrm{Na}$ verdade, estes temas não se excluem. O que é o narcisismo da visão, por exemplo? Nos cursos sobre a Natureza, Merleau-Ponty já havia comentado:

“ora, ver implica a possibilidade de se ver — lacuna de minha imagem visual de mim. Mas esta lacuna é compensada pela realização da imagem total fora de mim - a visão torna possível algo como o espelho - i.e. 'fantasma': minha imagem no espelho é algo de mim nas coisas (por este espelho tátil) que posso contemplar." (MERLEAU-PONTY, 1956-1960/1995, p.345)

“Tornar possível algo como um espelho”: o narcisismo da visão seria essa operação do olhar pela qual algo de meu está no que vejo, assim como algo de outro está na minha visibilidade. Trata-se de uma promiscuidade do olhar, de introjetar-projetar algo de meu em outro e algo de outro em mim.

Mas essa operação só é possível porque faço parte dessa visibilidade: sou algo que vê e, por isso, necessariamente, algo visível. Do mesmo modo, há algo de invisível em mim, mesmo que haja algo de outro nesse corpo visível. Há algo que pertence à Visibilidade: seu verso de invisibilidade.

Entretanto, o pertencimento a essa generalidade significa também ser ameaçado de ser visto, e ainda mais; isto nos coloca numa dimensão em que os artistas nos denunciam com toda vividez: sou visto pelas coisas, pois há um 
“quiasma eu-mundo: as coisas me olham. Eu me olho (pelos olhos das coisas)" (MERLEAU-PONTY, 1959, p.29).

Do mesmo modo, as coisas reclamam para serem vistas, assim como na aparência dos animais, nas suas plumagens, por exemplo, que reclamam uma comunicação: “(...) a coisa é, não reduzida ao percepi, mas aquilo que reclama, como uma propriedade sua, de ser visível ou vista (...) — a relação com a coisa é de projeção-introjeção, nós somos o verso e o reverso de um do outro. A coisa, articulação, transição, matriz, neste sistema de projeção-introjeção." (MERLEAUPONTY,1957, p.164)

Em L'oeil et l'esprit, Merleau-Ponty deixa ainda mais claro essa reversibilidade do olhar (e também uma não coincidência — uma juntura à distância): ao olhar um quadro, parece que é ele que me olha:

“é por isso que tanto pintores dizem que as coisas os olham, e André Marchand antes de Klee: 'Numa floresta, senti-me muitas vezes que não sou eu que olhava a floresta. Senti, nalguns dias, que foram as árvores que me olhavam, que falavam comigo... Eu estava lá, escutando... Eu acreditava que a pintura deveria ser transpassada pelo universo e não querer o transpassar... Espero ser interiormente submergido, englobado. Eu pinto talvez para surgir’. Aquilo que denominamos inspiração deveria ser tomado ao pé da letra: há verdadeiramente inspiração e expiração do Ser, respiração no Ser, ação e paixão são tão pouco discerníveis que não se sabe mais quem vê e quem é visto, quem pinta e quem é pintado." (MERLEAU-PONTY, 1964/2004b, p.31-32)

Ser transpassado pelas coisas, talvez não haja modo mais explícito de dizer que 0 mundo me invade... A tal ponto em que nem se sabe mais quem vê e quem é visto, quem motiva ou reclama essa participação na Visibilidade do mundo.

Se Merleau-Ponty destaca certo narcisismo, é para dizer que há uma junção à distância insuperável. Se, por um lado eu sou um corpo, sou algo visível; por outro, sou vidente. Esse é um fato jamais superável.

Porém, isto não impede de dizer, ao mesmo tempo, que minha proximidade ao mundo é de tal monta que não saberia mais dizer quem vê e quem é visto. Ao dizer que participamos da Visibilidade do mundo, podemos encontrar um "lugar” de dissolução do sujeito ou de um anonimato de mim mesmo: "Eu, verdadeiramente, é ninguém, é o anônimo; é preciso que seja assim, anterior a toda objetivação, denominação, para ser o Operador, ou aquilo do qual tudo vem." (MERLEAU-PONTY, 1964/2004b, p.294)

Podemos perceber, assim, como um diálogo, aparentemente sem muita importância na obra de Merleau-Ponty, uma vez que só aparece esboçado nos seus cursos e em notas esparsas dos seus últimos escritos, é fundamental para 
compreendermos uma das passagens mais enigmáticas de sua experiência filosófica: o narcisismo da visão.

Como vimos, este debate é privilegiado, pois, ao interrogar a psicanálise, o filósofo encontrou certas articulações que talvez não fossem possíveis de outro modo. O que visamos destacar aqui é como a noção de inconsciente em Freud, vinculada aos fenômenos paranormais, forneceu uma via para esse diálogo.

Ora, se estes fenômenos, para Freud, podem ser explicados a partir do problema do inconsciente, para Merleau-Ponty, essa explicação aponta para uma nova abertura. Num primeiro momento, o filósofo associa este conceito a uma lógica gestaltista figura/fundo - a premonição é como uma impercepção. Mas, nessa associação, Merleau-Ponty não elucida o que era mais obscuro para Freud: como explicar uma comunicação entre os inconscientes?

Este diálogo em torno dos fenômenos paranormais só foi retomado na obra de Merleau-Ponty em seus últimos escritos, quiçá um modo de dizer que uma questão talvez deva ser "colocada de lado" para depois ser retomada com outros olhos. Doravante, não basta dizer que o inconsciente é uma impercepção, mas sim que é um conceito fundamental para pensar a própria Visibilidade do mundo - tema maior do que pretendia uma fenomenologia da percepção.

Dizer que os inconscientes se comunicam significa agora afirmar que ter um corpo é participar dessa comunicação: saber que está sendo visto, sentir que se é olhado e que se está condenado à Visibilidade. O curioso é que se trata de textos "marginais" do psicanalista. Isto soa contraintuitivo, mas nos diz, ao mesmo tempo, que é justamente lá onde Freud parece querer forçar os limites da psicanálise que MerleauPonty encontra aquilo que ele considera a tendência de Freud: pensar o inconsciente como o sentir.

Recebido em 2/5/2011. Aprovado em 28/6/2011.

\section{REFERÊNCIASS}

BAAS, B. (1998) De la chose à l'objet — Jacques Lacan et la traversée de la phénoménologie. Leuven: Peeters: Vrin.

FREUD, S. (1905/1953) Historias clínicas de la psicoanálisis I. Traducción del Luis López-Ballesteros y de Torres. Buenos Aires: Santiago Rueda. (1919/1996) “O estranho”, in Obras psicológicas completas de Sigmund Freud, v.XVII. Rio de Janeiro: Imago.

DEVereuX, G. (ed). (1953) Psychoanalysis and the occult. London: A condor book.

MANZI, R. F. (2009) O caso Dora segundo Merleau-Ponty, Revista Brasileira de Psicanálise. São Paulo, v.43, série 1, 145-154. 
MERLEAU-PONTY, M. (1945/1967) Phénoménologie de la perception. Paris: Gallimard.

(1954-1955/2003) L’institution, la passivité. Paris: Belin.

(1956-1960/1995) La nature — Notes de cours du Collège de France.

Paris: Seuil.

. (1957) La nature ou le monde du silence, v. VI (BN: 9587). Inédito.

(1957-1958) Le concept de nature; L’animalité, le corps humanin, passage à

la culture, v.XVI (BN). Inédito.

(1959) Etre et monde, v.VI et VII (BN). Inédito.

(1959-1960) Nature et logos: le corps humain, v.XVII (BN). Inédito.

(1964/2004a) L'oeil et l'esprit. Paris: Gallimard.

(1964/2004b) Le visible et l'invisible. Paris: Gallimard.

PORTMANN, A. (1967) Animal forms and patterns - a study of the appearance of animals. Translated by Hella Czech. New York: Schocken Books.

Ronaldo Manzi Filho

manzifilho@hotmail.com 